\title{
$\alpha$-Synuclein Expression Modulates Microglial Activation Phenotype
}

\author{
Susan A. Austin, Angela M. Floden, Eric J. Murphy, and Colin K. Combs \\ Department of Pharmacology, Physiology, and Therapeutics, University of North Dakota, School of Medicine and Health Sciences, Grand Forks, North \\ Dakota 58202-9037
}

Recent Parkinson's disease research has focused on understanding the function of the cytosolic protein, $\alpha$-synuclein, and its contribution to disease mechanisms. Within neurons, $\alpha$-synuclein is hypothesized to have a role in regulating synaptic plasticity, vesicle release, and trafficking. In contrast, glial-expressed $\alpha$-synuclein remains poorly described. Here, we examine the consequence of a loss of $\alpha$-synuclein expression on microglial activation. Using a postnatal brain-derived culture system, we defined the phenotype of microglia from wildtype and knock-out $\alpha$-synuclein mice $\left(S c n a^{-1-}\right)$. Scna ${ }^{-1-}$ microglia displayed a basally increased reactive phenotype compared with the wild-type cells and an exacerbated reactive phenotype after stimulation. They also exhibited dramatic morphologic differences compared with wild-type, presenting as large, ramified cells filled with vacuole-like structures. This corresponded with increased protein levels of activation markers, CD68 and $\beta 1$ integrin, in the Scna ${ }^{-1-}$ cells. More importantly, Scna ${ }^{-1-}$ microglia, after stimulation, secreted elevated levels of proinflammatory cytokines, TNF $\alpha$ (tumor necrosis factor $\alpha$ ) and IL-6 (interleukin-6), compared with wild type. However, despite the reactive phenotype, $S_{c n a}{ }^{-1-}$ cells had impaired phagocytic ability. We demonstrate for the first time that $\alpha$-synuclein plays a critical role in modulating microglial activation state. We suggest that altered microglial $\alpha$-synuclein expression will affect their phenotype as has already been demonstrated in neurons. This has direct ramifications for the contribution of microglia to the pathophysiology of disease, particularly in familial cases linked to altered $\alpha$-synuclein expression.

Key words: microglia; TNF $\alpha$; $\alpha$-synuclein; phagocytosis; inflammation; Parkinson

\section{Introduction}

Overexpression and mutations in $\alpha$-synuclein are associated with early-onset Parkinson's disease (PD) (Polymeropoulos et al., 1997; Kruger et al., 1998; Singleton et al., 2003). It is aggregated intracellularly as a component of Lewy bodies characteristic of Parkinson's as well as other neurodegenerative diseases collectively referred to as synucleinopathies (Perry et al., 1990; Spillantini and Goedert, 2000). $\alpha$-Synuclein belongs to a family of three proteins and is highly conserved among vertebrates (for review, see Clayton and George, 1998). It is highly expressed in the brain in both glia and neurons, in areas including the thalamus, substantia nigra, caudate nucleus, hippocampus, amygdala, and subthalamic nucleus (Shibayama-Imazu et al., 1993; Ueda et al., 1993, 1994). It is found in presynaptic terminals of neurons (Maroteaux et al., 1988; McLean et al., 2000), but also in other regions of neurons as well as within astrocytes and oligodendro-

Received April 27, 2006; revised Aug. 17, 2006; accepted Sept. 7, 2006.

This work was supported by National Institutes of Health (NIH)-National Center for Research Resources Grant 1 P20 RR17699-01 (C.K.C., E.J.M.) and NIH-National Institute of Neurological Disorders and Stroke Grant 1R21NS043697-01A (E.J.M.). We thank Dr. Robert Nussbaum for his useful discussion and critical review of this manuscript. We also thank Joe Bertelsen of Signet Laboratories, Inc., for the generous gift of the $\alpha$-synuclein 4D6 antibody.

Correspondence should be addressed to Dr. Colin K. Combs, Department of Pharmacology, Physiology, and Therapeutics, University of North Dakota, School of Medicine and Health Sciences, 504 Hamline Street, Neuroscience Building, Grand Forks, ND 58202. E-mail: ccombs@medicine.nodak.edu.

D0I:10.1523/JNEUROSCI.1799-06.2006

Copyright $\odot 2006$ Society for Neuroscience $\quad$ 0270-6474/06/2610558-06\$15.00/0 glia (Richter-Landsberg et al., 2000; Mori et al., 2002). $\alpha$-Synuclein binds a variety of proteins (Jenco et al., 1998; Peng et al., 2005) and lipid vesicles (Cole et al., 2002), and is involved in lipid metabolism (Cabin et al., 2002; Castagnet et al., 2005; Golovko et al., 2005, 2006). Absence of $\alpha$-synuclein expression is associated with striatal dysfunction (Abeliovich et al., 2000). These data support the hypothesis that $\alpha$-synuclein may regulate vesicle trafficking and release by altering lipid membrane stability, intracellular lipid uptake, and metabolism.

Whereas the function of neuronal $\alpha$-synuclein continues to be characterized, the role of $\alpha$-synuclein in regulating glial physiology remains poorly defined. Recent studies in human astrocytes and macrophages have demonstrated an increase in $\beta$-and $\alpha$-synuclein expression, respectively, after stimulation with lipopolysaccharide (LPS) and interleukin-1 (IL-1), suggesting a role for $\alpha$-synuclein in the inflammatory process (Tanji et al., 2001, 2002). Few studies have reported the expression and function of this protein within microglia. Although microglial activation in vivo correlates with fibrillar $\alpha$-synuclein deposition and fibrillar $\alpha$-synuclein is capable of activating microglia in vitro, it is unclear what role its expression plays in regulating microglial behavior (Croisier et al., 2005; Zhang et al., 2005). We hypothesized that expression of the protein itself may also alter microglia reactivity. Here, we present results using an in vitro microglia culture system from wild-type $\alpha$-synuclein-expressing mice and $\alpha$-synuclein gene-ablated mice, Scna ${ }^{-1-}$, to characterize the phenotype differences caused by lack of $\alpha$-synuclein expression. 
A

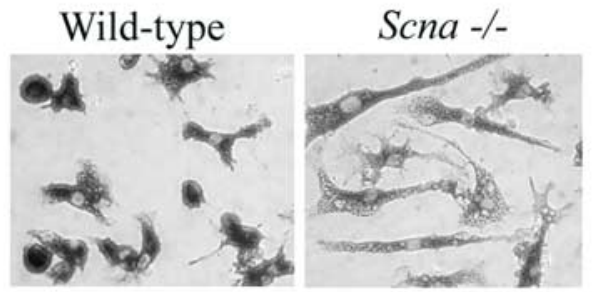

B
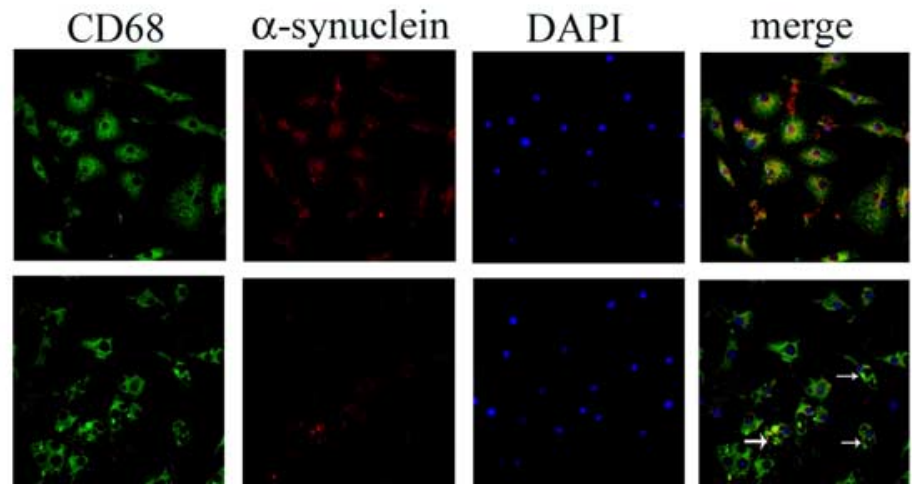

Figure 1. Microglia from Scna ${ }^{-1-}$ mice display a ramified, heavily vacuole-laden phenotype in vitro compared with wildtype microglia. Microglia were isolated from $14 \mathrm{~d}$ in vitro mixed glia cultures and plated onto tissue culture plastic for $24 \mathrm{~h}$. $A$, Cells were fixed in 4\% paraformaldehyde and immunostained with an anti-CD68 antibody. Antibody binding was visualized using Vector VIP as the chromagen. $\boldsymbol{B}$, Cells were double-labeled using anti-CD68 and anti- $\alpha$-synuclein antibodies with FITC-and Texas Red-conjugated secondary antibodies, respectively. Nuclei were stained with DAPI before mounting for confocal imaging. Contrast of merged images was increased to better illustrate double label. The arrows indicate large vacuole-like structures present in Scna ${ }^{-1-}$ microglia.

\section{Materials and Methods}

Materials. The anti- $\beta 1$ integrin, extracellular signal-regulated kinase 2 (ERK2), and horseradish peroxidase-conjugated secondary antibodies were purchased from Santa Cruz Biotechnology (Santa Cruz, CA). LPS and anti- $\alpha$-tubulin, a mouse monoclonal $\operatorname{IgG}_{2 \mathrm{~B}}$ antibody (catalog \#T 6793) were purchased from Sigma (St. Louis, MO). The anti-CD68 antibody was purchased from Serotec (Raleigh, NC). The anti- $\alpha$-synuclein (Syn-1) antibody is a mouse $\mathrm{IgG}_{1}$ antibody purchased from BD Transduction Laboratories (San Diego, CA) (catalog \#610786). The 4D6 anti$\alpha$-synuclein is a mouse monoclonal IgG antibody and was a gift from Signet Laboratories (Dedham, MA) (catalog \#9720-02). FITC-labeled Escherichia coli (K-12 strain) Bioparticles were purchased from Invitrogen (Eugene, OR).

Mice. Synuclein gene-ablated mice (129/SvEv), Scna ${ }^{-/-}$, were generated and characterized as described previously (Cabin et al., 2002). $\mathrm{Scna}^{-/-}$and Scna ${ }^{+/+}$(wild-type) mice were derived by crossing Scna ${ }^{+/-}$ heterozygotes to create appropriate genotypes (Ellis et al., 2005).

Tissue culture. Microglia were derived from postnatal day 1 (P1) to P2 wild-type and Scna ${ }^{-1-}$ mouse brains as described previously (Floden et al., 2005). Briefly, meninges-free cortices are isolated, trypsinized, and plated onto tissue culture flasks with feeding every fifth day. At $14 \mathrm{~d}$ in vitro, microglia were harvested from the mixed culture by rapid shaking (120 rpm; $30 \mathrm{~min}$ ) and plated for use. Microglial purity is routinely verified at $>98 \%$ by CD68 immunoreactivity.

Quantitation of secreted tumor necrosis factor $\alpha$ and IL-6. Microglia were plated at a density of 40,000 cells/well in serum-free DMEM/F-12 onto 96-well tissue culture plates for $24 \mathrm{~h}$ with and without $25 \mathrm{ng} / \mathrm{ml} \mathrm{LPS}$. After stimulation, medium was removed from the cultures and concentrations of secreted tumor necrosis factor $\alpha$ (TNF $\alpha$ ) and IL-6 were determined using commercially available mouse TNF $\alpha$ and IL- 6 colorimetric sandwich ELISA plates purchased from R \& D Systems (Minneapolis,
Wild-type

$\mathrm{MN})$. Experiments were performed with eight replicates per condition and repeated a minimum of three times. Data are presented as mean values $( \pm \mathrm{SD})$, and statistical significance was determined by unpaired one-way ANOVA with Tukey-Kramer's post hoc comparison $(p<0.05)$.

Phagocytosis assay. Phagocytosis was quantified by measuring the uptake of FITC-labeled bioparticles. Briefly, microglia were plated into 96-well plates (40,000 cells/well) and incubated with or without FITC-labeled bioparticles $(0.25$ $\mathrm{mg} / \mathrm{ml}$ ) for $3 \mathrm{~h}$. To quench the signal from extracellular or outer plasma membraneassociated bioparticles, the medium was removed and the cells were rinsed with 0.25 $\mathrm{mg} / \mathrm{ml}$ trypan blue in PBS. Intracellular fluorescence was read via fluorescent plate reader (Bio-Tek, Winooski, VT) at $480 \mathrm{~nm}$ excitation and $520 \mathrm{~nm}$ emission. Experiments were performed with eight replicates per condition and repeated a minimum of three times. Data are presented as mean values ( $\pm \mathrm{SD})$, and statistical significance was determined by unpaired ANOVA with Tukey-Kramer's post hoc comparison $(p<0.05)$.

Immunocytochemistry. To perform culture immunocytochemistry, microglia were plated in serum-free DMEM/F-12 for $24 \mathrm{~h}$, fixed in $4 \%$ paraformaldehyde $\left(37^{\circ} \mathrm{C} ; 30\right.$ min), immunostained using anti-CD68, and visualized using Vector VIP as the chromagen (Vector Laboratories, Burlingame, CA). Immunofluorescent double labeling was performed using anti-CD68 and Syn-1 antibodies with FITC- and Texas Red-conjugated secondary antibodies.

Western blot. To perform Western blot analyses, microglia were plated in serum-free DMEM/F-12 for $24 \mathrm{~h}$ with or without LPS ( $50 \mathrm{ng} / \mathrm{ml}$ ). Cells were collected, and lysates were quantified. Proteins were resolved by $10 \%$ SDS-PAGE, transferred to polyvinylidene difluoride membranes and Western blotted using anti- $\beta 1$ integrin, $\alpha$-tubulin, CD68, ERK2 (loading control), or $\alpha$-synuclein (4D6) antibodies. Blots were probed with affinity-purified horseradish peroxidase-conjugated secondary antibodies, and antibody binding was visualized by enhanced chemiluminescence. Optical density of protein bands were quantitated using Adobe Photoshop software. Quantitation data are presented as mean values ( \pm SD), and statistical significance was determined by unpaired ANOVA with Tukey-Kramer's post hoc comparison $\left({ }^{\star} p<0.05 ;{ }^{\star *} p<0.001\right)$.

\section{Results}

\section{Microglia from Scna ${ }^{-1-}$ mice are morphologically different from wild-type microglia}

To begin defining the role of $\alpha$-synuclein expression in modulating microglial activation, we first compared the morphological phenotype between $\mathrm{Scna}^{-1-}$ and wild-type microglia. We chose to use the common postnatal brain-derived microglia culture system for these studies based on our previous experience with this model (Sondag and Combs, 2004; Floden et al., 2005). Microglia were cultured from P1-P2 mouse brains from both Scna ${ }^{-1-}$ and wild-type animals for $14 \mathrm{~d}$ in vitro in parallel, and then isolated and plated for use in identical conditions. Although both $\mathrm{Scna}^{-1-}$ and wild-type microglia were robustly immunoreactive for the microglial marker protein, $\mathrm{CD} 68$, the morphologies dramatically differed (Fig. 1A,B). The Scna ${ }^{-1-}$ microglia were flat and ramified and heavily burdened with vacuole-like 
A

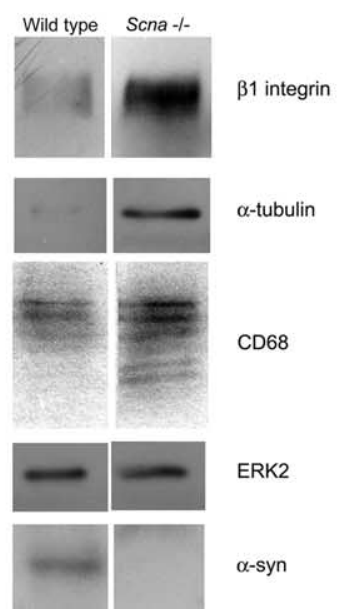

B

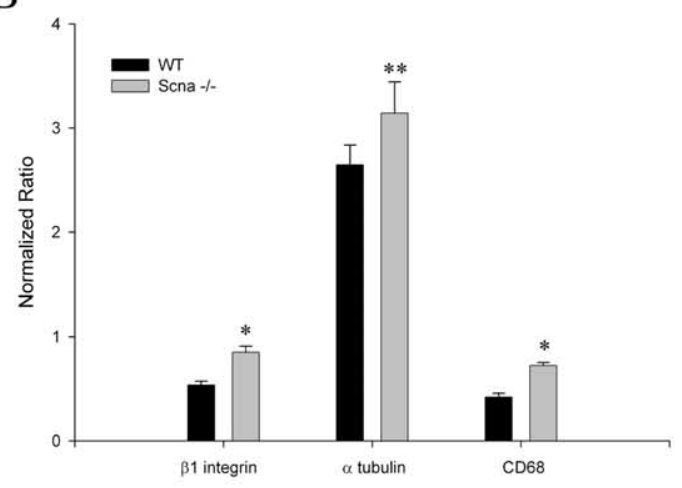

$\mathrm{C}$

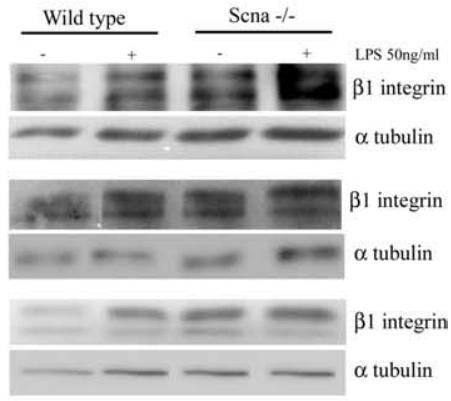

Figure 2. Microglia from Scna ${ }^{-1-}$ mice display increased levels of reactive marker proteins compared with wild-type microglia. Microglia from P1-P2 Scna ${ }^{-1-}$ and wild-type mice were cultured for $14 \mathrm{~d}$ in vitro as mixed glia cultures. At $14 \mathrm{~d}$ in vitro, microglia were isolated and plated for $24 \mathrm{~h}$. $A$, Cells were lysed, and proteins were resolved by $10 \%$ SDS-PAGE. Lysates were Western blotted using anti- $\beta 1$ integrin, $\alpha$-tubulin, and CD68 antibodies. Equal protein loading was verified using an anti-ERK2 antibody (loading control). $\boldsymbol{B}, 0$ ptical density of $\beta 1$ integrin, $\alpha$-tubulin, and CD68 protein bands from five independent culture preparations derived from different litters were normalized against respective ERK2 levels and averaged $( \pm S D)\left({ }^{* *} p<0.001\right.$ and ${ }^{*} p<0.05$ from respective control). C, Microglia isolated at $14 \mathrm{~d}$ in vitro were stimulated with or without $50 \mathrm{ng} / \mathrm{ml}$ LPS for $24 \mathrm{~h}$, and then lysed, and proteins were resolved by $10 \%$ SDS-PAGE. Lysates from three independent culture preparations from different litters were immunoblotted using anti- $\beta 1$ integrin and $\alpha$-tubulin antibodies. Blots were visualized via enhanced chemiluminescence.

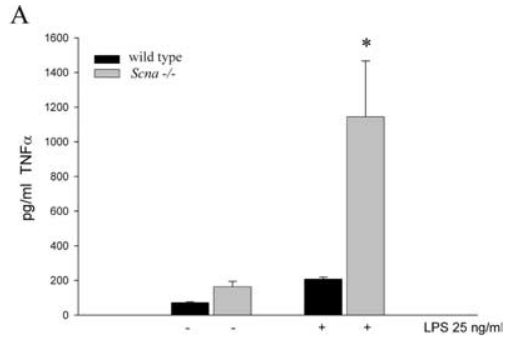

B

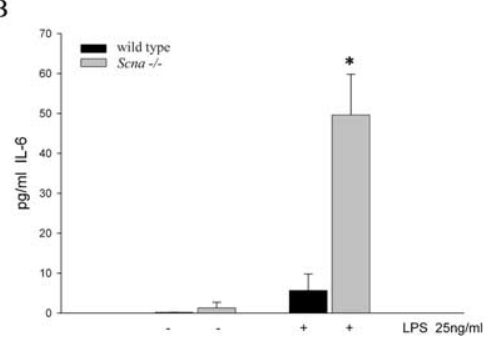

Figure 3. Microglia from Scna ${ }^{-1-}$ mice secrete increased levels of proinflammatory cytokines after stimulation compared with wild-type microglia. Microglia were isolated from $\mathrm{Scna}^{-1-}$ and wild-type mixed glia cultures at $14 \mathrm{~d}$ in vitro and plated in the absence or presence of $25 \mathrm{ng} / \mathrm{ml}$ LPS for $24 \mathrm{~h}$. Conditioned medium was collected from the cells and secreted TNF $\alpha(\boldsymbol{A})$ and IL-6 $(\boldsymbol{B})$ concentrations were determined using commercial ELISA. Graphs are representative of four independent experiments. Each experiment was performed with eight replicates per condition, and values were averaged ( \pm SD). ${ }^{*} p<0.001$ from respective control.

structures compared with their wild-type counterparts. To confirm the purity of our cultures and microglial expression of $\alpha$-synuclein, we fluorescently labeled the cultured cells with CD68, Syn-1, and 4' '6' -diamidino-2-phenylindole (DAPI) (Fig. $1 B)$. Together, these data confirm microglial expression of $\alpha$-synuclein and suggest that the basal activation state of the two cell types in vitro is different.

\section{Microglia from Scna ${ }^{-1-}$ mice displayed increased levels of reactive marker proteins}

To verify the hypothesized difference in basal activation state, we next compared protein levels of well characterized microgliareactive marker proteins, CD68 and $\beta 1$ integrin, in $\mathrm{Scna}^{-{ }^{--}}$and wild-type cells. Microglia were isolated from mixed glia cultures after $14 \mathrm{~d}$ in vitro and analyzed by Western blot. Increased basal levels of both CD68 and $\beta 1$ integrin were observed in the Scna ${ }^{-1-}$ microglia compared with wild-type cells consistent with the idea that the Scna ${ }^{-1-}$ microglia may be basally activated (Fig. 2A). Scna ${ }^{-1-}$ microglia also displayed an increase in protein levels of the cytoskeletal protein $\alpha$-tubulin compared with wild-type cells, consistent with the dramatic, ramified morphology we observed (Figs. 1, 2A). Quantitative analysis of the Western blots from multiple cultures showed statistically higher reactive protein levels in the $S \mathrm{cna}^{-/-}$microglia than wild-type microglia (Fig. 2B). These data support the idea that Scna ${ }^{-1-}$ microglia are basally reactive compared with wild-type cells.

It is known that microglia, after stimulation, increase their expression of a number of proteins, including $\beta 1$ integrins examined above (Milner and Campbell, 2003). To determine whether stimulation further differentiated the Scna ${ }^{-/-}$microglia from wildtype cells, we stimulated them with a well characterized, potent proinflammatory stimulus, bacterial endotoxin, LPS, before again performing Western blots for $\beta 1$ integrin and $\alpha$-tubulin. As expected, wild-type microglia showed increased levels of $\beta 1$ integrin and $\alpha$-tubulin after stimulation indicative of their activation (Fig. $2 C)$ and to approximately the level seen in the unstimulated Scna ${ }^{-1-}$ microglia (Fig. 2C). Stimulation of the Scna ${ }^{-1-}$ microglia also resulted in additional increases in both protein levels (Fig. 2C). These data suggest that the Scna ${ }^{-1-}$ cells become hyperreactive compared with wild-type cells after proinflammatory stimulation.

Microglia from Scna ${ }^{-/-}$mice secreted increased amounts of proinflammatory cytokines, TNF $\alpha$ and IL-6, after stimulation To quantitatively assess the basal and stimulated reactivity of the Scna ${ }^{-1-}$ cells, we measured secretion of two cytokines, TNF $\alpha$ 


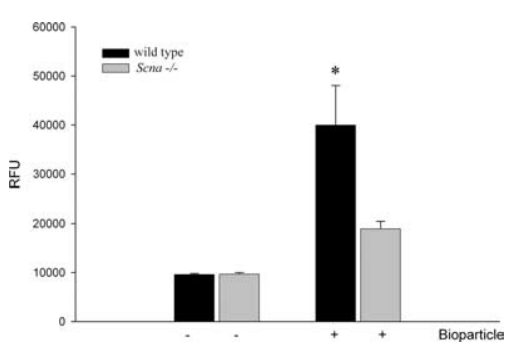

Figure 4. Microglia from Scna ${ }^{-1-}$ mice have decreased phagocytic ability compared with wild-type microglia. Microglia from Scna $a^{-1-}$ and wild-type control mice were cultured as mixed glia for $14 \mathrm{~d}$ in vitro. Microglia were isolated at $14 \mathrm{~d}$ and plated with or without FITClabeled E. coli bioparticles $(0.25 \mathrm{mg} / \mathrm{ml})$ for $3 \mathrm{~h}$. After the incubation, the medium was removed and the signal from unphagocytosed or extracellular membrane-associated FITC-labeled bioparticles was quenched by rinsing with $0.25 \mathrm{mg} / \mathrm{ml}$ trypan blue solution. Fluorescence intensity [relative fluorescence units (RFU)] of phagocytosed bioparticles was measured via a fluorescent plate reader ( $480 \mathrm{~nm}$ excitation and $520 \mathrm{~nm}$ emission) and averaged ( \pm SD). Each condition was performed with eight replicates, and the graph is representative of three independent experiments. ${ }^{*} p<0.001$ from respective control.

and IL-6, from wild-type and Scna ${ }^{-1-}$ microglia under unstimulated and LPS-stimulated conditions. Consistent with our morphologic and Western blot assays, Scna ${ }^{-1-}$ and wild-type microglia basally secreted both cytokines, although no significant differences were seen (Fig. $3 A, B$ ). More importantly, after stimulation, $S c n a^{-1-}$ microglia secreted significantly larger amounts of both cytokines (Fig. $3 A, B$ ). These data demonstrated that $S_{c n a}{ }^{-1-}$ cells have a hyperreactive phenotype after proinflammatory stimulation.

\section{Microglia from Scna ${ }^{-/-}$mice displayed decreased phagocytic ability}

Although cytokine secretion and morphologic changes are typical assays for defining microglial activation states, we further defined the differences between cells by using a more functional measure of reactivity, phagocytic ability. Just as there are multiple activation states in microglia, many phagocytic pathways exist as well. We examine one of these phagocytic pathways here; others may be unaffected. We compared phagocytic ability between the two cell types as a final assay of activation state differences by quantitating uptake of FITC-conjugated Escherichia coli bioparticles. Wild-type microglia phagocytosed a significantly greater amount of bioparticle compared with the Scna ${ }^{-1-}$ cells (Fig. 4). Therefore, although knock-out cells secrete elevated levels of cytokines after stimulation and present with a reactive morphology, they are deficient in phagocytic ability. These data demonstrate the complexity of the activation phenotype induced by the loss of $\alpha$-synuclein expression.

\section{Discussion}

After stimulation, microglia undergo several changes to adopt a reactive phenotype. Activated microglia alter expression of a variety of proteins, including cell adhesion molecules, such as ICAM-1 (intercellular adhesion molecule 1 ) and $\beta 1$ integrin, cytokines, such as TNF $\alpha$ and IL-6, and costimulatory molecules, such as MHC II (major histocompatibility complex II) (Frohman et al., 1991; Boka et al., 1994; McGeer et al., 1988, 2001). Microglia use these proteins to increase their adhesion and migration ability, to restructure their cytoskeleton to assist in phagocytosis and migration, and to stimulate surrounding cells via secretion (Thomas, 1992). Although this is a typical phenotype displayed by active microglia, it is not the only activation state these cells acquire. It is now appreciated that a spectrum of microglial activation states exist (Mantovani et al., 2002; Gordon, 2003).

The microglial phenotype induced by $\alpha$-synuclein deficiency represents one such atypical activation state. We have observed that Scna ${ }^{-1-}$ microglia have a ramified, vacuolar morphology with increased cytokine secretion and decreased phagocytic ability. Although disparate characteristics, they are all a consequence of the absence of $\alpha$-synuclein expression. These observations demonstrate that $S \mathrm{cna} \mathrm{I}^{-1-}$ microglia have a somewhat reactive phenotype basally compared with wild-type cells. In addition, Scna ${ }^{-1-}$ microglia are capable of even further increased activation after stimulation compared with their wild-type counterparts. Despite this, however, knock-out microglia have decreased phagocytic ability. Perhaps this is not entirely surprising given the fact that heightened phagocytic activity of microglia is generally associated with an ameboid morphology similar to that of our wild-type cells (Smith and Hoerner, 2000). More importantly, increased phagocytic ability is not an integral characteristic of an activated phenotype. Certainly, alternative activation states describe microglia with a typical proinflammatory phenotype but a reduced ability to phagocytose (Mantovani et al., 2002; Gordon, 2003).

Although we have not yet determined the mechanism by which $\alpha$-synuclein regulates microglial activation, it is intriguing to speculate that the mechanism may involve alteration in lipid-mediated signal transduction. Lipid-dependent signaling pathways are an integral component of many stimuli leading to microglia activation. For example, phospholipase D (PLD) activity is required for macrophage activation in response to a variety of proinflammatory stimuli including LPS and TNF $\alpha$ (De Valck et al., 1993). PLD activity also contributes to cytoskeletal restructuring and phagocytosis ability of microglia and macrophage (Iyer et al., 2004). $\alpha$-Synuclein interacts with PLD isozymes, which results in inhibition of enzymatic activity (Jenco et al., 1998; Ahn et al., 2002), and overexpression of $\alpha$-synuclein potently inhibits PLD (Outeiro and Lindquist, 2003). We have demonstrated increased palmitic acid turnover in phosphatidylcholine in the $\alpha$-synuclein-deficient mouse brains, indicating increased PLD activity resulting from $\alpha$-synuclein deficiency (Golovko et al., 2005). In addition, our recent work suggested that $\alpha$-synuclein expression also modulates $\mathrm{PLA}_{2}$ (phospholipase $\mathrm{A}_{2}$ )dependent signaling events. We have linked $\alpha$-synuclein to 20:4n-6 metabolism via its impact on endoplasmic reticulum localized acyl-CoA synthetases (Golovko et al., 2006). Mutant forms of $\alpha$-synuclein (A30P, E46K, A53T) fail to modulate acyl-CoA synthetase activity, suggesting potential derangement of arachidonic acid metabolism and eicosanoiddependent signaling in the brain (Golovko et al., 2006). Together, these data support the idea that $\alpha$-synuclein may modulate microglial activation by regulating proinflammatory lipid-dependent signaling events.

It will also be important to define the consequences of $\alpha$-synuclein overexpression and mutant expression on microglial phenotype, because these conditions represent the situations responsible for familial PD. This is particularly relevant given the possibility that disease mutations result in loss of function. This would indicate that microglial activation from mutant synuclein expression plays a direct role in the pathophysiology of disease. An active role for microglia during selective dopaminergic loss certainly correlates with the fact that the substantia nigra represents a brain region particularly concentrated with microglia (Kim et al., 2000). Moreover, PD brains have a maintained pres- 
ence of reactive microglia (McGeer and McGeer, 2004; Teismann and Schulz, 2004) that increase in number with disease duration (Croisier et al., 2005). Finally, positron emission tomography has shown that early-stage PD brains have increased microglial reactivity positively correlating with disease motor severity (Ouchi et al., 2005). These data demonstrate that altered microglial phenotype is an early induced, yet maintained disease histopathology and likely an important contributor to disease pathophysiology. Although microglial activation in vivo correlates with fibrillar $\alpha$-synuclein deposition and that fibrillar $\alpha$-synuclein is capable of activating microglia in vitro (Croisier et al., 2005; Zhang et al., 2005), our work suggests that altered or mutant microglial $\alpha$-synuclein expression may result in a direct contribution by these cells to the proinflammatory state and neuron loss characteristic of PD.

\section{References}

Abeliovich A, Schmitz Y, Farinas I, Choi-Lundberg D, Ho W-H, Castillo PE, Shinsky N, Verdugo JMG, Armanini M, Ryan A, Hynes M, Phillips H, Sulzer D, Rosenthal A (2000) Mice lacking $\alpha$-synuclein display functional deficits in the nigrostriatal dopamine system. Neuron 25:239-252.

Ahn BH, Rhim H, Kim SY, Sung YM, Lee MY, Choi JY, Wolozin B, Chang JS, Lee YH, Kwon TK, Chung KC, Yoon SH, Hahn SJ, Kim MS, Jo YH, Min do S (2002) Alpha-synuclein interacts with phospholipase D isozymes and inhibits pervanadate-induced phospholipase D activation in human embryonic kidney-293 cells. J Biol Chem 277:12334-12342.

Boka G, Anglade P, Wallach D, Javoy-Agid F, Agid Y, Hirsch EC (1994) Immunocytochemical analysis of tumor necrosis factor and its receptors in Parkinson's disease. Neurosci Lett 172:151-154.

Cabin DE, Shimazu K, Murphy D, Cole NB, Gottschalk W, McIlwain KL, Orrison B, Chen A, Ellis CE, Paylor R, Lu B, Nussbaum RL (2002) Synaptic vesicle depletion correlates with attenuated synaptic responses to prolonged repetitive stimulation in mice lacking $\alpha$-synuclein. J Neurosci 22:8797-8807.

Castagnet PI, Golovko MY, Barcelo-Coblijn GC, Nussbaum RL, Murphy EJ (2005) Fatty acid incorporation is decreased in astrocytes cultured from alpha-synuclein gene-ablated mice. J Neurochem 94:839-849.

Clayton DF, George JM (1998) The synucleins: a family of proteins involved in synaptic function, plasticity, neurodegeneration and disease. Trends Neurosci 21:249-254.

Cole NB, Murphy DD, Grider T, Rueter S, Brasaemle D, Nussbaum RL (2002) Lipid droplet binding and oligomerization properties of the Parkinson's disease protein alpha-synuclein. J Biol Chem 277:6344-6352.

Croisier E, Moran LB, Dexter DT, Pearce RK, Graeber MB (2005) Microglial inflammation in the parkinsonian substantia nigra: relationship to alpha-synuclein deposition. J Neuroinflammation 2:14.

De Valck D, Beyaert R, Van Roy F, Fiers W (1993) Tumor necrosis factor cytotoxicity is associated with phospholipase D activation. Eur J Biochem 212:491-497.

Ellis CE, Murphy EJ, Mitchell DC, Golovko MY, Scaglia F, Barcelo-Coblijn GC, Nussbaum RL (2005) Mitochondrial lipid abnormality and electron transport chain impairment in mice lacking $\alpha$-synuclein. Mol Cell Biol 25:10190-10201.

Floden AM, Li S, Combs CK (2005) $\beta$-Amyloid-stimulated microglia induce neuron death via synergistic stimulation of tumor necrosis factor $\alpha$ and NMDA receptors. J Neurosci 25:2566-2575.

Frohman EM, Frohman TC, Gupta S, de Fougerolles A, van den Noort S (1991) Expression of intercellular adhesion molecule 1 (ICAM-1) in Alzheimer's disease. J Neurol Sci 106:105-111.

Golovko MY, Faergeman NJ, Cole NB, Castagnet PI, Nussbaum RL, Murphy EJ (2005) Alpha-synuclein gene deletion decreases brain palmitate uptake and alters the palmitate metabolism in the absence of alphasynuclein palmitate binding. Biochemistry 44:8251-8259.

Golovko MY, Rosenberger TA, Faergeman NJ, Feddersen S, Cole NB, Pribill I, Berger J, Nussbaum RL, Murphy EJ (2006) Acyl-CoA synthetase ac- tivity links wildtype but not mutant a-synuclein to brain arachidonate metabolism. Biochemistry 45:6956-6966.

Gordon S (2003) Alternative activation of macrophages. Nat Rev Immunol 3:23-35.

Iyer SS, Barton JA, Bourgoin S, Kusner DJ (2004) Phospholipases D1 and D2 coordinately regulate macrophage phagocytosis. J Immunol 173:2615-2623.

Jenco JM, Rawlingson A, Daniels B, Morris AJ (1998) Regulation of phospholipase D2: selective inhibition of mammalian phospholipase D isoenzymes by $\alpha$ - and $\beta$-synucleins. Biochemistry 37:4901-4909.

Kim WG, Mohney RP, Wilson B, Jeohn GH, Liu B, Hong JS (2000) Regional difference in susceptibility to lipopolysaccharide-induced neurotoxicity in the rat brain: role of microglia. J Neurosci 20:6309-6316.

Kruger R, Kuhn W, Muller T, Woitalla D, Graeber M, Kosel S, Przuntek H, Epplen JT, Schols L, Riess O (1998) Ala30Pro mutation in the gene encoding alpha-synuclein in Parkinson's disease. Nat Genet 18:106-108.

Mantovani A, Sozzani S, Locati M, Allavena P, Sica A (2002) Macrophage polarization: tumor associated macrophages as a paradigm for polarized M2 mononuclear phagocytes. Trends Immunol 23:549-555.

Maroteaux L, Campanelli JT, Scheller RH (1988) Synuclein: a neuronspecific protein localized to the nucleus and presynaptic nerve terminals. J Neurosci 8:2804-2815.

McGeer PL, McGeer EG (2004) Inflammation and neurodegeneration in Parkinson's disease. Parkinsonism Relat Disord 10:S3-S7.

McGeer PL, Itagaki S, Boyes BE, McGeer EG (1988) Reactive microglia are positive for HLA-DR in the substantia nigra of Parkinson's and Alzheimer's disease brains. Neurology 38:1285-1291.

McGeer PL, Yasojima K, McGeer EG (2001) Inflammation in Parkinson's disease. Adv Neurol 86:83-89.

McLean PJ, Ribich S, Hyman BT (2000) Subcellular localization of alphasynuclein in primary neuronal cultures: effect of missense mutations. J Neural Transm Suppl 53-63.

Milner R, Campbell IL (2003) The extracellular matrix and cytokines regulate microglial integrin expression and activation. J Immunol 170:3850-3858.

Mori F, Tanji K, Yoshimoto M, Takahashi H, Wakabayashi K (2002) Demonstration of alpha-synuclein immunoreactivity in neuronal and glial cytoplasm in normal human brain tissue using proteinase $\mathrm{K}$ and formic acid pretreatment. Exp Neurol 176:98-104.

Ouchi Y, Yoshikawa E, Sekine Y, Futatsubashi M, Kanno T, Ogusu T, Torizuka T (2005) Microglial activation and dopamine terminal loss in early Parkinson's disease. Ann Neurol 57:168-175.

Outeiro TF, Lindquist S (2003) Yeast cells provide insight into alphasynuclein biology and pathobiology. Science 302:1772-1775.

Peng X, Tehranian R, Dietrich P, Stefanis L, Perez RG (2005) Alphasynuclein activation of protein phosphatase $2 \mathrm{~A}$ reduces tyrosine hydroxylase phosphorylation in dopaminergic cells. J Cell Sci 118:3523-3530.

Perry RH, Irving D, Blessed G, Fairbairn A, Perry EK (1990) Senile dementia of Lewy body type. A clinically and neuropathologically distinct form of Lewy body dementia in the elderly. J Neurol Sci 95:119-139.

Polymeropoulos MH, Lavedan C, Leroy E, Ide SE, Dehejia A, Dutra A, Pike B, Root H, Rubenstein J, Boyer R, Stenroos ES, Chandrasekharappa S, Athanassiadou A, Papapetropoulos T, Johnson WG, Lazzarini AM, Duvoisin RC, Di Iorio G, Golbe LI, Nussbaum RL (1997) Mutation in the alpha synuclein gene identified in families with Parkinson's disease. Science 276:2045-2047.

Richter-Landsberg C, Gorath M, Trojanowski JQ, Lee VM (2000) alphaSynuclein is developmentally expressed in cultured rat brain oligodendrocytes. J Neurosci Res 62:9-14.

Shibayama-Imazu T, Okahashi I, Omata K, Nakajo S, Ochiai H, Nakai Y, Hama T, Nakamura Y, Nakaya K (1993) Cell and tissue distribution and developmental change of neuron specific $14 \mathrm{kDa}$ protein (phosphoneuroprotein 14). Brain Res 622:17-25.

Singleton AB, Farrer M, Johnson J, Singleton A, Hague S, Kachergus J, Hulihan M, Peuralinna T, Dutra A, Nussbaum R, Lincoln S, Crawley A, Hanson M, Maraganore D, Adler C, Cookson MR, Muenter M, Baptista M, Miller D, Blancato J, et al. (2003) alpha-Synuclein locus triplication causes Parkinson's disease. Science 302:841. 
Smith ME, Hoerner MT (2000) Astrocytes modulate macrophage phagocytosis of myelin in vitro. J Neuoroimmunol 154:154-162.

Sondag CM, Combs CK (2004) Amyloid precursor protein mediates proinflammatory activation of monocytic lineage cells. J Biol Chem 279:14456-14463.

Spillantini MG, Goedert M (2000) The alpha-synucleinopathies: Parkinson's disease, dementia with Lewy bodies, and multiple system atrophy. Ann NY Acad Sci 920:16-27.

Tanji K, Mori F, Nakajo S, Imaizumi T, Yoshida H, Hirabayashi T, Yoshimoto M, Satoh K, Takahashi H, Wakabayashi K (2001) Expression of betasynuclein in normal human astrocytes. NeuroReport 12:2845-2848.

Tanji K, Mori F, Imaizumi T, Yoshida H, Matsumiya T, Tamo W, Yoshimoto M, Odagiri H, Sasaki M, Takahashi H, Satoh K, Wakabayashi K (2002) Upregulation of alpha-synuclein by lipopolysaccharide and interleukin-1 in human macrophages. Pathol Int 52:572-577.
Teismann P, Schulz JB (2004) Cellular pathology of Parkinson's disease: astrocytes, microglia and inflammation. Cell Tissue Res 318:149-161.

Thomas WE (1992) Brain macrophages: evaluation of microglia and their functions. Brain Res Rev 1:61-74.

Ueda K, Fukushima H, Masliah E, Xia Y, Iwai A, Yoshimoto M, Otero DA, Kondo K, Ihara Y, Saitoh T (1993) Molecular cloning of cDNA encoding an unrecognized component of amyloid in Alzheimer's disease. Proc Natl Acad Sci USA 90:11282-11286.

Ueda K, Saitoh T, Mori H (1994) Tissue-dependent alternative splicing of messenger-RNA for NACP, the precursor of non-A- $\beta$ component of Alzheimer's disease. Biochem Biophys Res Commun 205:1366-1372.

Zhang W, Wang T, Pei Z, Miller DS, Wu X, Block ML, Wilson B, Zhou Y, Hong JS, Zhang J (2005) Aggregated alpha-synuclein activates microglia: a process leading to disease progression in Parkinson's disease. FASEB J 19:533-542. 